Letters to the Editor NEUROSURGICAL FORUM

\section{Arachnoid cyst and the hemorrhagic complications of open decompression}

TO THE EDITOR: The report authored by Auschwitz et al. ${ }^{1}$ (Auschwitz T, DeCuypere M, Khan N, et al: Hemorrhagic infarction following open fenestration of a large intracranial arachnoid cyst in a pediatric patient. J Neurosurg Pediatr 15:203-206, February 2015) shows another example of our lack of precise understanding of the underlying pathophysiology of intracranial arachnoid cyst and the impact of this cyst on CSF dynamic and cerebral autoregulation, as well as our lack of a well-rounded treatment algorithm for this condition.

The best treatment approach for intracranial arachnoid cysts is considered controversial in current neurosurgical practice. Most neurosurgeons prefer endoscopic or microscopic fenestration over shunt insertion as the method of choice for the initial treatment modality for symptomatic arachnoid cyst, and if this treatment modality fails, CSF shunting is considered as the next treatment option.

The main reason for favoring fenestration over shunting is to avoid ending up with a shunt-dependent patient. Despite this rationale for avoiding CSF shunting as the first treatment step for symptomatic arachnoid cyst, however, we have observed during our practice in treating this condition that open fenestration of arachnoid cysts is associated with high rates of complications and a high failure rate. In fact, this observation is also reported by others. For example, Choi et al. recently published a report of 75 patients who underwent surgical treatment (fenestration) for intracranial arachnoid cyst, with a 36-month median follow-up period. They reported a successful rate of only $28 \%$ (21 patients) and a total of 35 complications occurring in 28 patients (37\%). ${ }^{3}$ Nevertheless, some authors documented a better outcome with intracranial arachnoid fenestration; however, it is undeniable that some complications of this kind of treatment are extremely serious (such as postoperative intraparenchymal hemorrhage) ${ }^{1,2}$

Intracranial arachnoid cyst is considered a congenital condition, although there are reports of intracranial cysts that developed spontaneously de novo or after trauma. ${ }^{7}$ Based on several observations, this condition may in fact represent a kind of CSF dynamic disorder. It seems that patients harboring an intracranial arachnoid cyst develop with time some new CSF pathways and a unique dynamic balance between the cyst and the other CSF compartments. This may explain why most arachnid cysts are asymptomatic. It also explains why some cysts increase in size, decrease in size, or appear spontaneously; why sometimes the symptoms are just transitory; and why shunting sometimes leads to unusual CSF dynamic phenomena. ${ }^{4-7,9}$

If intracranial arachnoid cyst represents a CSF dynamic disorder, it is rational to assume that these lesions should also be associated with cerebral perfusion and cerebral autoregulation disorder (because both the CSF dynamic and cerebral blood flow are connected through the underling physiology decribed in the Monro-Kellie doctrine). ${ }^{8}$ It has been shown that the Monro-Kellie doctrine operates not only to prevent critically high intracranial pressure (ICP) but also to prevent critically low ICP. ${ }^{8}$ This concept may be important in explaining the hemorrhagic complication reported by Auschwitz et al. The sudden decompression of the cyst (sudden removal of a large volume of CSF) might cause the ICP to become critically low, and as a result the blood is accumulated intracranially as a compensation mechanism. This whole process can be looked at as a kind of acute ICP homeostasis failure that happened because of the acute decompression of the cyst.

That being said, one of the important questions regarding the optimal treatment of intracranial arachnoid cyst is how much we can interfere with the well-established CSF dynamic balance during the course of the treatment. Thus, we also need to know the best way to ensure that our intervention remains under control. Shunting may be the best answer for these questions, especially with the advances in shunt technology (programmable shunt) and the advances in imaging guidance that may enable us to make the shunt procedure for treatment of intracranial arachnoid cyst even more minimally invasive, which may represent another important advantage over fenestration. Therefore, perhaps we should change our current popular paradigm of treatment strategies of intracranial arachnoid cyst and move from fenestration toward shunting as the initial treatment modality for the symptomatic intracranial arachnoid cyst, or maybe we should refine our surgical technique of open arachnoid cyst decompression in a way that respects the underlying abnormal CSF dynamic.

Yet, in addition to conducting well-designed randomized clinical studies for CSF shunting versus fenestration, we strongly believe that the ultimate answer regarding the best treatment for intracranial arachnoid cysts requires conducting more research efforts that aim to achieve a better understanding of the changes in CSF pathways that develop in patients with intracranial arachnoid cysts, and how these pathways are affected by fenestration and 
shunting. This may give us more insights into why some patients develop symptoms, the reason for some serious complications after fenestration, and why some patients become shunt dependent.

Asem Salma, MD
Maher Hassounah, MD
Essam Alshail, MD
Ibrahim Althubaiti, MD
King Faisal Specialist Hospital and Research Centre, Riyadh,
Saudi Arabia

\section{DISCLOSURE}

The authors report no conflict of interest.

\section{References}

1. Auschwitz T, DeCuypere M, Khan N, Einhaus S: Hemorrhagic infarction following open fenestration of a large intracranial arachnoid cyst in a pediatric patient. J Neurosurg Pediatr 15:203-206, 2015

2. Bahl A, Connolly DJ, Sinha S, Zaki H, McMullan J: Rapid brain shift, remote site hemorrhage, and a spinal hematoma after craniotomy for a large arachnoid cyst. J Pediatr Neurosci 7:106-108, 2012

3. Choi JW, Lee JY, Phi JH, Kim SK, Wang KC: Stricter indications are recommended for fenestration surgery in intracranial arachnoid cysts of children. Childs Nerv Syst 31:77-86, 2015

4. Hassounah MI, Rahm BE: Hindbrain herniation: an unusual occurrence after shunting an intracranial arachnoid cyst. Case report. J Neurosurg 81:126-129, 1994

5. Lee JY, Kim JW, Phi JH, Kim SK, Cho BK, Wang KC: Enlarging arachnoid cyst: a false alarm for infants. Childs Nerv Syst 28:1203-1211, 2012

6. Menon RK, Wester KG: A boy with arachnoid cyst, a fall, and temporary and reversible visual impairment. Pediatr Neurol 51:834-836, 2014

7. Russo N, Domenicucci M, Beccaglia MR, Santoro A: Spontaneous reduction of intracranial arachnoid cysts: a complete review. Br J Neurosurg 22:626-629, 2008

8. Salma A: Normal pressure hydrocephalus as a failure of ICP homeostasis mechanism: the hidden role of Monro-Kellie doctrine in the genesis of NPH. Childs Nerv Syst 30:825830,2014

9. Struck AF, Murphy MJ, Iskandar BJ: Spontaneous development of a de novo suprasellar arachnoid cyst. Case report. J Neurosurg 104 (6 Suppl):426-428, 2006

\section{Response}

We appreciate the comments of Salma et al. regarding our case report. Their theoretical discussion of a possible scenario that might occur with sudden decompression of the brain (i.e., drainage of a large cyst) is interesting; however, there are other pathological conditions, both acute and chronic, in which surgical treatment results in the same phenomenon-a rapid decompression of pressure in the brain - such as removal of large clots, abscesses, or drainage of a large tumor cyst. Fortunately the complication of hemorrhagic infarction, as seen in this scenario, is very rare, but that makes our ability to understand the risk factors difficult.

We have hypothesized that when an arachnoid cyst warrants treatment and when there are signs of significantly increased ICP present, using an approach that would al- low a gradual initial decompression might help avoid this complication. We are not suggesting, however, nor do we agree with the authors, that the overall treatment paradigm should shift to shunting.

Stephanie Einhaus, MD

Semmes-Murphey Neurologic \& Spine Institute, Memphis, TN

\section{INCLUDE WHEN CITING}

Published online July 24, 2015; DOI: 10.3171/2015.1.PEDS1552.

(cAANS, 2015

\section{Hemorrhagic infarction following open fenestration of intracranial arachnoid cyst}

TO THE EDITOR: Having read with interest the recent article by Auschwitz et al. ${ }^{1}$ (Auschwitz T, DeCuypere M, Khan N, et al: Hemorrhagic infarction following open fenestration of a large intracranial arachnoid cyst in a pediatric patient. J Neurosurg Pediatr 15:203-206, February 2015), we would like to make a few comments based on our own experience with the same pathology. ${ }^{3,4}$

First, endoscopic cystoventriculostomy is recommended in the treatment of symptomatic arachnoid cyst, and we think that this technique is the gold standard in the treatment of intracranial arachnoid cyst. Endoscopic treatment maintains the basic strategy of cyst fenestration into the lateral ventricle or basal cisterns without the invasiveness of open craniotomy. The procedure is simple, effective, and minimally invasive; it saves operative and recovery time; and it is associated with low morbidity and mortality rates. ${ }^{2}$ In our opinion, craniotomy is only indicated in cases of complicated arachnoid cyst with an intracystic hemorrhage, or with rupture into the subdural space causing brain compression and midline shift. We agree with the authors that craniotomy with fenestration produces a rapid reduction in intracranial pressure leading to changes in the cerebral circulation and resulting in cerebral hemorrhage.

Second, the authors believe that by implanting a shunt it is possible to progressively reduce intracranial pressure. We fully agree with this statement, but today we do not consider the shunt a good treatment option because it eventually presents numerous avoidable complications. ${ }^{5}$

Finally, the authors state that "subdural hematomas and hygromas have rarely been reported as complications of arachnoid cyst and subdural hematomas are widely reported throughout the literature." However, in our experience it is not unusual for bruising to occur in low-intensity trauma, causing subdural hygromas or chronic subdural hematoma, especially in young patients.

Miguel Gelabert-González, PhD Lara Pita-Buezas, MD

Eduardo Arán-Echabe, MD

University of Santiago de Compostela, Santiago de Compostela, Spain 
DISCLOSURE

The authors report no conflict of interest.

\section{References}

1. Auschwitz T, DeCuypere M, Khan N, Einhaus S: Hemorrhagic infarction following open fenestration of a large intracranial arachnoid cyst in a pediatric patient. J Neurosurg Pediatr 15:203-206, 2015

2. El-Ghandour NM: Endoscopic treatment of intraparenchymal arachnoid cysts in children. J Neurosurg 14:501-507, 2014

3. Gelabert M, Fernandez JM, Cutrín JM, Garcia A, Martinez R: Arachnoid cysts rupture with subdural hygroma. Report of three cases and literature review. Childs Nerv Syst 18:609613,2002

4. Gelabert-González M: [Intracranial arachnoid cyst.] Rev Neurol 39:1161-1166, 2004 (Span)

5. Li C, Yin L, Jiang T, Ma Z, Jia G: Shunt dependency syndrome after cystoperitoneal shunting of arachnoid cysts. Childs Nerv Syst 30:471-476, 2014

\section{Response}

We would like to thank Gelabert-González et al. for their interest in our article. The authors begin by stating that they consider endoscopic cystoventriculostomy to be the "gold standard" treatment for arachnoid cysts. Gold standard is a term used to describe a method or procedure that is widely recognized as the best available. At present, there is not a randomized controlled trial comparing open and endoscopic techniques in the treatment of intracranial arachnoid cysts, and, although they may offer their opinion, they do not offer data to support the claim that endoscopic fenestration is a gold standard. We would agree that the minimally invasive approach works well and can be used in certain arachnoid cysts, but not all. The authors agreed with us that the cause of the intracranial hemorrhage in this case of open fenestration might have been from rapid decompression of the cyst; however, rapid decompression can also occur with endoscopic fenestration. Thus, endoscopic techniques do not necessarily protect a patient from rapid decompression. We would also agree that shunts should be avoided whenever possible with this pathology. We bring up the use of a shunt, however, as a possible way to reduce the occurrence of rapid decompression in very large arachnoid cysts. Furthermore, there are times when patients with arachnoid cysts have underlying CSF absorption issues and fenestration is not definitive. In this case, they may ultimately require a CSF shunting procedure.

We have reported a very rare complication with the use of a commonly performed procedure for large intracranial arachnoid cysts. At present, treatment strategies for this pathology are controversial. Because the majority of arachnoid cysts are not treated endoscopically at present, the authors may offer their opinion, but we would encourage that they avoid the use of terms like "gold standard" without appropriate data to support their conclusions.

Stephanie Einhaus, MD Semmes-Murphey Neurologic \& Spine Institute, Memphis, TN

\section{INCLUDE WHEN CITING}

Published online July 24, 2015; DOI: 10.3171/2014.12.PEDS14725.

CAANS, 2015

\section{Chiari malformation I and autism spectrum disorder}

TO THE EDITOR: We read with interest the article by Jayarao et al. ${ }^{4}$ (Jayarao M, Sohl K, Tanaka T: Chiari malformation I and autism spectrum disorder: an underrecognized coexistence. J Neurosurg Pediatr 15:96-100, January 2015). The authors suggest that clinicians should be aware of a greater frequency of Chari I malformation (CMI) in children with a diagnosis of autism spectrum disorder (ASD). The authors reviewed the cases of 125 patients with ASD who had been referred for cranial MRI. As the authors noted, cranial MRI is not generally recommended for the routine evaluation of children with ASD. ${ }^{3,5,8}$ In their group of patients who had been selected to undergo imaging, the authors found 9 patients they considered to have "tonsillar herniation," yielding an imaging prevalence of $7.2 \%$ in those with ASD. On this basis, they concluded that CMI was overrepresented in patients with ASD. We are concerned that this conclusion is not well supported by the reported data.

Although somewhat controversial, the most widely accepted imaging definition of CMI requires cerebellar tonsil position to be at least $5 \mathrm{~mm}$ below the foramen magnum. ${ }^{1,2}$ Four of the 9 patients classified as having "tonsillar herniation" in this series had a tonsil position that was less than $5 \mathrm{~mm}$ below the foramen magnum. Tonsil position for these 4 patients was not specified except to note that they had a tonsil position $4 \mathrm{~mm}$ or less below the foramen magnum. If the more conventional 5-mm definition of CMI was applied to this group selected for imaging instead of an unspecified definition for "tonsillar herniation," this would result in a calculated imaging prevalence of $4 \%$ for CMI rather than the reported $7.2 \%$. As the authors acknowledge, in a large, previously reported series of pediatric patients undergoing MRI, the prevalence of CMI based on the most accepted 5-mm definition was 3.6\% ${ }^{6,7}$ We believe that a case has not yet been made to substantiate the assertion that the prevalence of CMI in children selected for imaging is meaningfully overrepresented in the ASD population. We agree with the authors that study of a larger population database must be undertaken, hopefully including large numbers of those without ASD, before arriving at any definite conclusions.

Jennifer Strahle, MD

Cormac O. Maher, MD

University of Michigan, Ann Arbor, MI

DISCLOSURE

The authors report no conflict of interest.

\section{References}

1. Aboulezz AO, Sartor K, Geyer CA, Gado MH: Position of cerebellar tonsils in the normal population and in patients with Chiari malformation: a quantitative approach with MR imaging. J Comput Assist Tomogr 9:1033-1036, 1985

2. Barkovich AJ, Wippold FJ, Sherman JL, Citrin CM: Significance of cerebellar tonsillar position on MR. AJNR Am J Neuroradiol 7:795-799, 1986

3. Filipek PA, Accardo PJ, Ashwal S, Baranek GT, Cook EH Jr, 
Dawson G, et al: Practice parameter: screening and diagnosis of autism: report of the Quality Standards Subcommittee of the American Academy of Neurology and the Child Neurology Society. Neurology 55:468-479, 2000

4. Jayarao M, Sohl K, Tanaka T: Chiari malformation I and autism spectrum disorder: an underrecognized coexistence. J Neurosurg Pediatr 15:96-100, 2015

5. Johnson CP, Myers SM: Identification and evaluation of children with autism spectrum disorders. Pediatrics 120:11831215,2007

6. Smith BW, Strahle J, Bapuraj JR, Muraszko KM, Garton HJ, Maher CO: Distribution of cerebellar tonsil position: implications for understanding Chiari malformation. J Neurosurg 119:812-819, 2013

7. Strahle J, Muraszko KM, Kapurch J, Bapuraj JR, Garton HJ, Maher CO: Chiari malformation Type I and syrinx in children undergoing magnetic resonance imaging. J Neurosurg Pediatr 8:205-213, 2011

8. Volkmar F, Cook EH Jr, Pomeroy J, Realmuto G, Tanguay P: Practice parameters for the assessment and treatment of children, adolescents, and adults with autism and other pervasive developmental disorders. American Academy of Child and Adolescent Psychiatry Working Group on Quality Issues. J Am Acad Child Adolesc Psychiatry 38 (12 Suppl):32S54S, 1999

\section{Response}

We thank Drs. Strahle and Maher for their comments related to our article and bringing to our attention concerns related to the "best definition" of CMI. Prior to submitting our manuscript for publication, there were extensive discussions among the authors in regards to the criteria for a diagnosis of CMI. We are aware that CMI has been defined by some as a position of the tonsils $5 \mathrm{~mm}$ below the foramen magnum. However, we elected to use a 3-mm position as a criterion for CMI, strictly following an article by Barkovich et al., ${ }^{1}$ which Drs. Strahle and Maher referenced. According to the Barkovich et al. study, the degree of cerebellar tonsillar ectopia is an imaging feature that most often corresponded to clinical significance. Ectopia of $2 \mathrm{~mm}$ or less is unlikely to be of clinical significance. If tonsils' tips extended $3 \mathrm{~mm}$ or more, patients usually exhibited symptoms. In fact, Barkovich and colleagues stated that only one patient with cerebellar ectopia $\geq 3 \mathrm{~mm}$ did not have symptoms. Therefore, we stand by this definition in our paper.

Since patients with an ASD have baseline difficulty in communicating their symptoms, our intention was to identify CMI in ASD patients by adhering as much as possible to objective methods. Thus, we chose to define tonsillar ectopia as that in which the tonsils are $3 \mathrm{~mm}$ below the foramen magnum. We realize that the prevalence of CMI will depend on which criterion is used. Since our study involved a small group, a larger ASD population will need to be analyzed. Also, we would like to emphasize the importance of obtaining brain MR images in patients with ASD. As we mentioned in article, the American Academy of Neurology, the Child Neurology Society, the American Academy of Child and Adolescent Psychiatry, and the American Academy of Pediatrics do not recommend imaging as part of the routine evaluation of children with ASD. Even when ASD patients whose parents and whose pediatricians suspect they have been experiencing symp- toms, the previous statement makes it difficult for the pediatricians to order imaging studies. Therefore, investigation of a larger population of patients with ASD will be very important for further clarification. After investigating a larger population along with a normal population, we may be able to define an accurate prevalence rate in both an ASD and a normal population of CMI.

Tomoko Tanaka, MD

University of Missouri School of Medicine, Columbia, MO

Mayur Jayarao, MD, MSc

Geisinger Health System, Danville, PA

Kristin Sohl, MD

Thompson Center for Autism and Developmental Disorders, University of Missouri, Columbia, MO

\section{Reference}

1. Barkovich AJ, Wippold FJ, Sherman JL, Citrin CM: Significance of cerebellar tonsillar position on MR. AJNR Am J Neuroradiol 7:795-799, 1986

\section{INCLUDE WHEN CITING}

Published online August 14, 2015; DOI: 10.3171/2015.2.PEDS1571.

(c)ANS, 2015

\section{Carbon dioxide laser and corpus callosotomy}

TO THE EDITOR: I have read with great interest the article recently published in the Journal of Neurosurgery: Pediatrics by Choudhri and colleagues ${ }^{1}$ (Choudhri O, Lober RM, Camara-Quintana J, et al: Carbon dioxide laser for corpus callosotomy in the pediatric population. $J$ Neurosurg Pediatr 15:321-327, March 2015). The authors describe the successful application of a handheld $\mathrm{CO}_{2}$ laser fiber tip well suited for working in the depths of the intrahemispheric fissure with minimal brain retraction. They point out that the dissection could be readily done layer by layer using the $\mathrm{CO}_{2}$ fiber. One of the disadvantages in using the fiber is that there are 2 instruments in the surgical field: the fiber and the suction tool. The latter is extremely important to have not only to wash away fluid and debris, but also to remove the plume.

A true advantage in dissecting with the $\mathrm{CO}_{2}$ aimed through a microscope is the elimination of the fiber from the visual field, as well as any other instrument in the surgical field. With the $\mathrm{CO}_{2}$ aimed through the microscope, the only instrument needed in the field is the surgical suction tool. By operating through the microscope, one truly has a "no touch" technique with minimal retraction and optimal visualization of the entire surgical field. In addition, you can eliminate trauma because the laser beam is aimed using the joystick on the microscope attachment (microslad). This technical advantage was pointed out by Robertson and Clark. ${ }^{2}$

I found this microdissection technique extremely useful not only for corpus callosotomies, but also for microresections in other tissues. I performed a corpus callosotomy 
with the same technique. The only disadvantage is adding the microslide to the microscope, which creates an increase in the distance between the microscope and the surgical field; however, the use of the microscope and the reduction of instruments in the surgical field compensate for this increased distance.

I wish to congratulate the authors for pointing out once more the advantage of $\mathrm{CO}_{2}$ laser surgery in neurological surgery.

Hector E. James, MD

Wolfson Children's Hospital/Baptist Medical Center, Jacksonville, FL University of Florida College of Medicine Jacksonville, Jacksonville, FL

DISCLOSURE

The author reports no conflict of interest.

\section{References}

1. Choudhri O, Lober RM, Camara-Quintana J, Yeom KW, Guzman R, Edwards MSB: Carbon dioxide laser for corpus callosotomy in the pediatric population. J Neurosurg Pediatr 15:321-327, 2015

2. Downing EF, Ascher PW, Cerullo LJ, Neblett CR, Robertson JH, Tew JM (eds): Lasers in Neurosurgery. Vienna: Springer, 1989

\section{Response}

We thank Dr. James for sharing his experience in using microscope-mounted lasers for corpus callosotomies in the past. Early on, $\mathrm{CO}_{2}$ laser systems were used with a microscope attachment known as a "microslad," which can be mounted to the inferior surface of the microscope. The microslad houses a mirror and a joystick to maneuver the laser beam anywhere within the microscope field. The addition of the laser attachment can make the microscope setup cumbersome and increases the microscope's dis- tance from the operative field. However, this setup does allow the application of laser energy with no instruments in the operative field and the ability to use the laser's cutting and coagulation properties with no additional manipulation.

Strait and colleagues described the use of this microscope-mounted $\mathrm{CO}_{2}$ laser system for the resection of intracranial meningiomas in $1982 .{ }^{1}$ In our experience, the flexible OmniGuide laser fiber is a compact system that allows the laser beam to be used in deeper spaces and at tighter angles with improved transmission of laser energy. It is also more easily adopted by neurosurgeons given its handheld design and ergonomics, as described in our paper. Even though microscopes with a laser-articulating arm predate the flexible $\mathrm{CO}_{2}$ laser, they definitely provided proof of concept for the lasers. In the future, a compact setup may allow incorporation of the OmniGuide $\mathrm{CO}_{2}$ laser within the machinery of an operating microscope to provide an added level of precision.

Omar Choudhri, MD

Raphael Guzman, MD

Michael S. B. Edwards, MD

Lucile Packard Children's Hospital at Stanford, Stanford, CA

\section{Reference}

1. Strait TA, Robertson JH, Clark WC: Use of the carbon dioxide laser in the operative management of intracranial meningiomas: a report of twenty cases. Neurosurgery 10:464-467, 1982

INCLUDE WHEN CITING

Published online August 28, 2015; DOI: 10.3171/2015.4.PEDS15247.

cAANS, 2015 